\title{
Evolution of helium signatures from Kermadec arc under water volcanoes
}

\author{
MAREN WALTER $^{1,2} *$, ANDREAS TÜRKE ${ }^{1,3}$, CHRISTIAN \\ MERTENS $^{2}$, JÜRGEN SÜLTENFUß ${ }^{2}$ \\ ${ }^{1}$ MARUM - Center for Marine Environmental Sciences, \\ Univ. Bremen, Germany (*mwalter@marum.de) \\ ${ }^{2}$ Institute of Environmental Physics, Univ. Bremen, Germany \\ ${ }^{3}$ Department of Geosciences, Univ. Bremen, Germany
}

\section{Method}

The isotopic signature $\mathrm{R}={ }^{3} \mathrm{He} /{ }^{4} \mathrm{He}$ of primordial helium in hydrothermal fluids and plumes is significantly different from the atmospheric ratio $(\mathrm{Ra})$ and can be identified with high precision in fluid/water samples. During the $R V$ Sonne expedition SO253, we sampled noble gas isotopes from four hydrothermal active volcanoes along the Kermadec arc (SW Pacific) with summit depths between 290 to $1200 \mathrm{~m}$ below the surface. We extend an existing time series of helium isotopes from the 1990s/2000s in this area [1-4] to observe changes in the underlying plumbing of the hydrothermal systems. The samples were analysed in the lab post-cruise using a combined QMS/SMS [5]. Primordial excess ${ }^{3} \mathrm{He}$ is reported as $\delta^{3} \mathrm{He}$, the deviation of $\mathrm{R}$ from $\mathrm{Ra}$ (in \%).

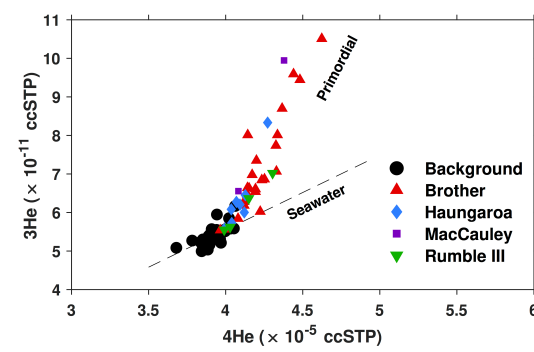

Figure 1:

He concentration from Kermadec volcanoes from 2017 (SO253).

\section{Results}

The ${ }^{3} \mathrm{He} /{ }^{4} \mathrm{He}$ ratios at the volcanoes vary between 5.8 and $6.5 \mathrm{Ra}$. The maximum $\delta^{3} \mathrm{He}$ at the non-buoyant plume level are: Rumble III 90\%, Haungaroa 83\%, Macauley Cone site 144\%, Macauley Caldera site 16\%, Brothers Cone site 56\%, Brothers NW Caldera site 94\%. The sites at Brothers and Macauley Caldera are relatively stable since the late 1990s/early 2000s [3, 5]. $\delta^{3} \mathrm{He}$ at Macauley Cone has increased tenfold since 2005 [4], and showed the highest $\delta^{3} \mathrm{He}$ of $445 \%$ in a weakly diluted sample $(\mathrm{pH}=5.0)$ from the rising plume $(<1 \mathrm{~m}$ above vent).

[1] de Ronde et al. (2001) EPSL 193, 359-369. [2] de Ronde et al. (2005) Econ. Geol. 100, 1097-1133. [3] de Ronde et al. (2007) G3. 8, Q07007. [4] de Ronde et al. (2011) Miner. Deposita 46, 541-584. [5] Sültenfuß et al. (2009) Isotopes Environ. Health Stud. 45, 1-13. 